\title{
Video-assisted thoracic surgery in spontaneous pneumothorax
}

\author{
Calvin SH Ng BSc MBBS, Song Wan MD PhD FRCS, Tak Wai Lee MB ChB FRCS, \\ Innes YP Wan MB ChB FRCS, Ahmed A Arifi MD FRCS, \\ Anthony PC Yim MD FRCS FACS
}

CSH Ng, S Wan, TW Lee, IYP Wan, AA Arifi, APC Yim. Video-assisted thoracic surgery in spontaneous pneumothorax. Can Respir J 2002;9(2):122-127.

The proven safety and efficacy of minimal access video-assisted thoracic surgery has changed the way that spontaneous pneumothorax is managed. This review presents some of the experiences of the decade, discusses the controversies and reviews the current video-assisted thoracic surgical management of spontaneous pneumothorax.

Key Words: Spontaneous pneumothorax; Thoracoscopy; Videoassisted thoracic surgery

\section{Pneumothorax spontané et chirurgie thoracique assistée par vidéo}

RÉSUMÉ : L'innocuité et l'efficacité avérées de la chirurgie thoracique assistée par vidéo, comportant une effraction minimale a changé le traitement du pneumothorax spontané. Le présent article fait état de certaines expériences menées au cours de la dernière décennie, des controverses actuelles et du traitement chirurgical assisté par vidéo des pneumothorax spontanés, mis en œuvre aujourd'hui.
$\mathrm{T}$ he history of therapeutic thoracoscopy can be traced back to the year 1910, when intrapleural pneumolysis for tuberculosis was performed by Jacobaeus (1). However, it is not until the last decade that technological advancements in videoendoscopy have enabled the re-introduction of thoracoscopy, with its increasing clinical application, in the form of video-assisted thoracoscopic surgery (VATS) (2). These advances are as follows: the improved rod lens coupled with the development of microcameras that allow for a panoramic view of the hemithorax (instead of the previous tunnel-like vision); improved anesthetic technique with one lung ventilation, permitting free manoeuvrability of the telescope and instruments; and availability of recently developed endoscopic surgical instruments such as the linear staple cutter, which has widened the spectrum of therapeutic procedures. Furthermore, the success and excitement of laparoscopic cholecystectomy gave impetus to the application of a similar technique to the chest.

Although controversy still exists, VATS is now regarded by many surgeons to be the approach of choice in the management of a variety of thoracic conditions such as spontaneous pneumothorax (SP), pleural diseases and indeterminate lung nodules.

Division of Cardiothoracic Surgery, Department of Surgery, The Chinese University of Hong Kong, Prince of Wales Hospital, Sha Tin NT, Hong Kong

Correspondence: Dr Anthony PC Yim, Professor and Chief, Division of Cardiothoracic Surgery, Department of Surgery, The Chinese University of Hong Kong, Prince of Wales Hospital, Sha Tin NT, Hong Kong. Telephone +852-2632-2629, fax +852-2637-7974, e-mailyimap@cuhk.edu.hk 


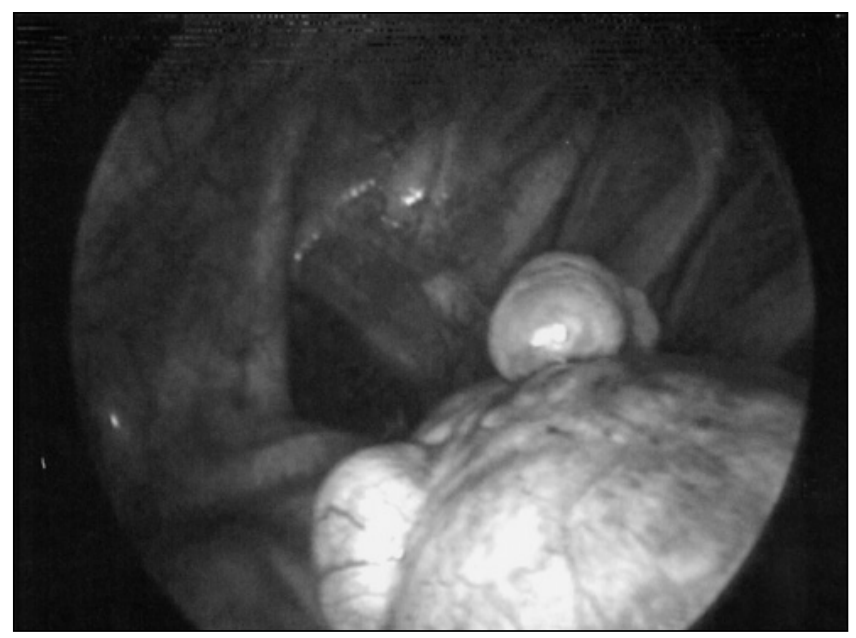

Figure 1) Bullae at the apex of right upper lobe in a patient with primary spontaneous pneumothorax

\section{SURGICAL MANAGEMENT: IS THERE A CONSENSUS?}

Currently, there is no good consensus on the treatment of first-time or recurrent primary SP (PSP) (3). Conservative management (observation, needle aspiration and chest tube) of SP has been shown to result in a significant recurrence rate of $16 \%$ to $52 \%$ (average $30 \%$ ), with most recurrences occurring within six months to two years (4). Furthermore, the rate of recurrence increases dramatically with more episodes of SP, and stopping an air leak becomes harder to achieve by conservative medical management (4).

With the lowered morbidity of VATS, the old surgical algorithms, based on the morbidity of thoracotomy, should be re-evaluated. The accepted surgical indications for pneumothorax include persistent air leak $(3,5)$, recurrence $(3,5)$, radiologically demonstrated huge bullae, spontaneous hemopneumothorax, incomplete expansion of the lung, tension pneumothorax, bilateral involvement and SP in a high risk occupation such as a pilot or scuba diver (3). Some authors have even recommended VATS for uncomplicated first-time pneumothorax (3), which we currently do not advocate. However, there remain many controversies on issues such as the duration of persistent air leak and the number of recurrences before surgery is deemed appropriate (3). A recent consensus statement from the American College of Chest Physicians recommended observation of air leaks for four days before surgical intervention (3). Our experience supports the use of VATS when a persistent air leak is present for more than three days and on the second admission for SP. However, in patients who are not suitable for surgery or general anesthesia, medical management in the form of talc pleurodesis should be considered $(3,6)$.

The role of surgical treatment for the future prevention of SP in the ipsi- and contralateral lung for high risk patients has also been divided. The question of whether radiological evidence of pulmonary bullae can predict pneumothorax occurrence or recurrence, and thereby select patients for 'prophylactic' VATS therapy, remains unanswered. Many people are sceptical of the causal relationship between bullae and PSP, but videoscopic findings have shown that a large proportion $(78 \%$ to $89 \%)$ of patients presenting with PSP in presumably normal lungs have endoscopically visible blebs or bullae (Figure 1, Table 1). Detecting the presence of bullae by computed tomography (CT) scan and thoracoscopy at the initial presentation of

TABLE 1

Video-assisted thoracoscopic surgery (VATS) for spontaneous pneumothorax: recent data

\begin{tabular}{|c|c|c|c|c|c|c|c|c|c|c|}
\hline $\begin{array}{l}\text { Author } \\
\text { (reference), } \\
\text { year }\end{array}$ & $\begin{array}{c}\text { Case } \\
\text { description }\end{array}$ & $\begin{array}{c}\text { Patient } \\
\text { (n) }\end{array}$ & $\begin{array}{c}\text { Blebs/ } \\
\text { bullae } \\
\text { seen at } \\
\text { VATS }(\%)\end{array}$ & $\begin{array}{c}\text { Stapled } \\
\text { bullectomy }\end{array}$ & $\begin{array}{c}\text { Endoloop/ } \\
\text { Endosuturing/ } \\
\text { ABC }\end{array}$ & $\begin{array}{c}\text { Abrasion } \\
\text { pleurodesis } \\
(\%)\end{array}$ & $\begin{array}{l}\text { Prolonged } \\
\text { postoperative } \\
\text { air leak (\%) }\end{array}$ & $\begin{array}{l}\text { Mean hospital M } \\
\text { hospital } \\
\text { stay in } \\
\text { days (range) }\end{array}$ & $\begin{array}{l}\text { Mean or median } \\
\text { follow-up in } \\
\text { months } \\
\text { (range) }\end{array}$ & $\begin{array}{c}\text { SP } \\
\begin{array}{c}\text { recurrence } \\
(\%)\end{array}\end{array}$ \\
\hline $\begin{array}{l}\text { Yim and Liu } \\
\text { (24), } 1997\end{array}$ & PSP & 483 & 87 & 196 & $261 / 35 / 6$ & $\begin{array}{l}100 \text { (alone in } \\
20 \text { cases) }\end{array}$ & 3 & $3(1-30)$ & $20(1-36)$ & 1.7 \\
\hline $\begin{array}{l}\text { Liu et al } \\
\qquad(25), 1999\end{array}$ & $\begin{array}{l}\text { PSP and } \\
\text { SSP }\end{array}$ & 757 & 89 & 312 & $352 / 52 / 6$ & $\begin{array}{l}\text { NA (alone in } \\
49 \text { cases) }\end{array}$ & 4 (>10 days) & $4.5(0-27)$ & $30(1-60)$ & 2.1 \\
\hline $\begin{array}{l}\text { Hatz et al } \\
(20), 2000\end{array}$ & $\begin{array}{l}\text { PSP and } \\
\text { SSP }\end{array}$ & $\begin{array}{l}P S P-95 \\
S S P-14\end{array}$ & NA & $\begin{array}{l}109 \text { (alone } \\
\text { in 72) }\end{array}$ & 0 & 34 & 2.8 (>2 days) & $\begin{array}{l}P S P-4(2-14) \\
S S P-8(1-18)\end{array}$ & $53(2-86)$ & 4.6 \\
\hline $\begin{array}{l}\text { Ayed and } \\
\text { Al-Din } \\
\text { (37), } 2000\end{array}$ & PSP & 72 & 78 & 56 & 0 & 54 & 6.9 (>5 days) & 4 & $42(36-54)$ & $\begin{array}{l}5.5 \text { (from } \\
\text { gauze } \\
\text { abrasion) }\end{array}$ \\
\hline $\begin{array}{l}\text { Loubani and } \\
\text { Lynch } \\
\text { (38), } 2000\end{array}$ & PSP & 49 & NA & $\begin{array}{l}52 \text { (with or } \\
\text { without } \\
\text { acromycin) }\end{array}$ & 0 & 0 & NA & $\begin{array}{l}\text { 6.8/4.8 (bullectomy/ } \\
\text { bullectomy with } \\
\text { acromycin) }\end{array}$ & $y / \quad 38(36-40)$ & $\begin{array}{c}\text { 20/4 (bullectomy/ } \\
\text { bullectomy with } \\
\text { acromycin) }\end{array}$ \\
\hline $\begin{array}{l}\text { Cardillo et al } \\
\text { (36), } 2000\end{array}$ & PSP & 432 & 78 & 235 & $104 / 0 / 0$ & 0 & 1.4 (>5 days) & 6 & $38(2-72)$ & 4.4 \\
\hline $\begin{array}{l}\text { Chan et al } \\
(16), 2001\end{array}$ & PSP & 82 & NA & NA & $\mathrm{NA} / 0 / 0$ & 100 & NA & NA & $44(8-85)$ & 5.7 \\
\hline
\end{tabular}

ABC Argon beam coagulation; NA Data not available; PSP Primary spontaneous pneumothorax; SP Spontaneous pneumothorax; SSP Secondary spontaneous pneumothorax 


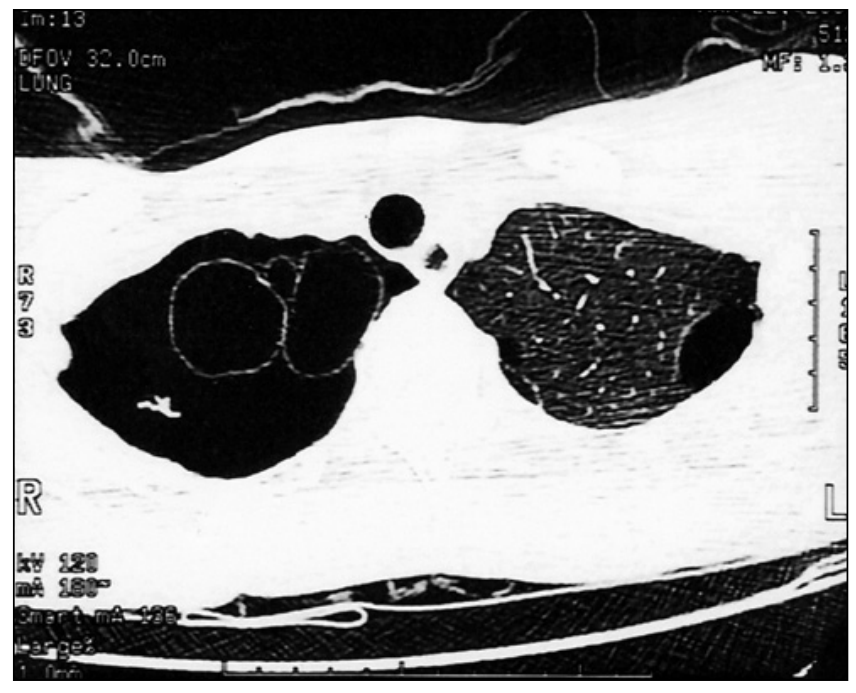

Figure 2) Computed tomography scan of the thorax of a 17-year-old man showing bilateral apical bullae and right-sided spontaneous pneumothorax. The initial spontaneous pneumothorax was treated with video-assisted thoracoscopic surgery, stapled bullectomy and abrasion pleurodesis. However, contralateral spontaneous pneumothorax occurred two days later

SP was shown not to predict recurrence (4). Interestingly, a recent study reported that the detection of bullae by CT scanning in the contralateral lung after unilateral PSP is associated with a higher rate of subsequent pneumothorax in that lung (7) (Figure 2). Thus, the value of VATS as primary therapy for PSP and in preventing ipsi- or contralateral pneumothorax occurrence by way of bulla detection with CT scans remains controversial. Additionally, there appears to be no consensus on the use of thoracic CT for evaluating patients with recurrent pneumothoraces or persistent air leaks (3). Results from carefully conducted randomized clinical trials are needed in these areas.

\section{VATS FOR PNEUMOTHORAX}

Surgical access for the management of pneumothorax can be obtained by open techniques (usually axillary or lateral thoracotomy) or by minimal access VATS. The success of VATS in the treatment of pneumothorax has led to earlier referral by physicians and increased acceptance of surgery by patients (8). The experience so far shows that VATS procedures in elderly patients (older than 75 years of age) are safe, with few postoperative pulmonary complications (9). In addition, VATS can also be a useful approach in selected cases of the pediatric population for a variety of endoscopic procedures (10).

There is increasing evidence to associate VATS with less access trauma and quicker recovery, with many doctors realizing that the trauma from access is often worse than the surgery (11). Postoperative proinflammatory cytokine levels are lower, and T (CD4) cells, as well as natural killer cells, are less suppressed after VATS compared with their open counterparts $(12,13)$. Also, patients undergoing VATS require significantly less postoperative parenteral

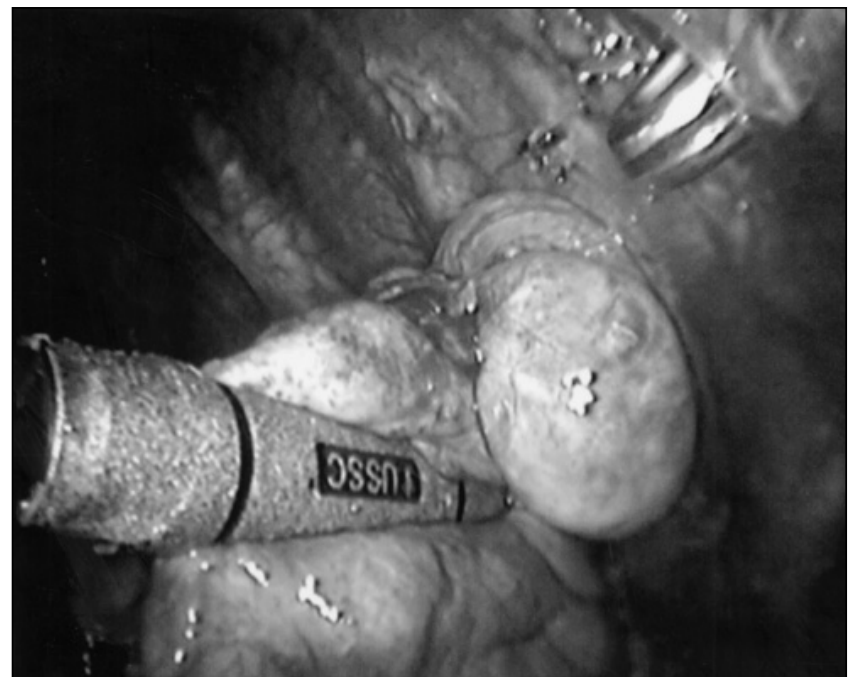

Figure 3) Endoscopic stapled bullectomy

narcotics than patients undergoing procedures using the open techniques (12). However, chronic sequelae (chronic pain, numbness or disesthesia) occur after $25 \%$ to $31 \%$ of thoracoscopic procedures; the rate of chronic pain is equal in VATS and thoracotomy (14-16). In our experience, many of the patients who underwent VATS for SP thought that the chest tube insertion (with or without sedation) was more painful than VATS.

Pulmonary function tests performed postoperatively after VATS for SP showed little deterioration compared with normal controls. In contrast, patients who underwent thoracotomy and parietal pleurectomy for SP had a 7.5\% to $16 \%$ reduction in vital capacity before returning to preoperative values after five months (17). The difference is likely to be attributed to access trauma from rib-spreading in thoracotomy.

\section{General approach}

The chest is the most suitable body cavity for minimal access surgery, because once the lung is collapsed (with selective one-lung ventilation), there is plenty of room for instrument manoeuvring. The use of carbon dioxide insufflation and hence valved ports is therefore unnecessary. In fact, there is evidence that thoracic carbon dioxide insufflation during VATS has an adverse effect on the patient's hemodynamics compared with selective one-lung ventilation (18).

The patient should be routinely positioned in the lateral decubitus position. The operating table is flexed to $30^{\circ}$ to open up the intercostal spaces for thoracoscope insertion and instrumentation. For exploratory thoracoscopy, we prefer to place the telescope low in the chest (seventh intercostal space, mid-axillary line) so that one can obtain a panoramic view of the hemithorax. Most procedures require two instrument ports, which should be inserted under direct thoracoscopic vision. The trocar sites should be at a suitable distance from the target lesion to provide space for manipulation. Furthermore, the instrument and 
camera ports should be sufficiently far apart in a 'triangulation' manner to prevent instrument 'fencing' and be within the same $180^{\circ}$ arc to avoid mirror imaging.

There are additional strategies in VATS that can assist in minimizing chest wall trauma and hence postoperative pain. These strategies include: rib-spreading may be unnecessary, because flexing of the operating table at the level of the minithoracotomy may adequately open up the intercostal space; avoiding the use of trocar ports by introducing instruments directly through the wound; avoiding torquing of the thoracoscope by using an angled lens; using smaller telescopes $(5 \mathrm{~mm})$ when clinically allowed; and delivering specimens through the anterior port, because the anterior intercostals spaces are wider (19).

\section{Endoscopic stapled bullectomy}

The presence of subpleural bullae has been reported in 76\% to $100 \%$ of PSP patients during VATS (5). Endoscopic stapled bullectomy remains the preferred procedure for bullectomy (Figure 3) (3) and should be accompanied by some form of pleurodesis (20). Complications associated with the technique include air leak from the staple line, especially in emphysematous patients (21), which can be greatly reduced by pericardial buttress reinforcement (22). Furthermore, malfunctioning of staple-cutters has also been reported (23).

\section{Endoscopic suturing}

Video-assisted thoracoscopic suturing of apical bullae with mechanical pleurodesis has been shown to be a viable alternative to endoscopic stapled bullectomy with mechanical pleurodesis $(8,24,25)$. Parenteral narcotic requirements, chest drainage duration, hospital stay and pneumothorax recurrence are similar for both techniques $(24,25)$. To minimize cost, the long conventional needle holder and standard monofilament polypropylene sutures were found to be as effective as specialized endoscopic suturing equipment for thoracoscopic suturing of bullae. Thus, in view of the high cost of staple-cutters, endoscopic suturing of apical bullae should be considered in selected cases of small, localized bullae for PSP $(8,24,25)$. However, it must be emphasized that endoscopic suturing should be performed by surgeons adequately trained in this skill.

\section{Endoloop ligation}

Endoscopic endoloop bulla ligation may be suitable for bullae in PSP and secondary SP $(25,26)$. It is performed using a pretied commercial endoloop or a homemade polydioxanone loop. Homemade devices are, of course, more cost effective. However, a known complication of endoloop ligation is the accidental slipping of the loop during lung expansion or after a forceful sneeze. The problem can be minimized by the placement of a double or triple loop around each bulla $(21,23)$.

\section{VATS for pneumothorax during pregnancy}

The third trimester, particularly near term, is the most common time for PSP to occur during pregnancy. Most cases result from the rupture of a subpleural apical bulla or bleb, precipitated by pulmonary and thoracic pressure changes. Difficulties in pneumothorax management during pregnancy are related to the reduced maternal respiratory reserve (diaphragmatic splinting), increased oxygen demand during pregnancy and labour, inadequate fetal oxygen supply and preterm labour. A chest drain should be inserted when the patient presents with a PSP in the first or second trimester, or early in the third trimester; then, VATS should be considered (27). However, if the patient presents near term and has a large pneumothorax, VATS should be delayed until early in the postpartum period. Preparations should be made for an emergency caesarian section in case of acute fetal distress.

\section{Limitations and complications}

There are relatively few contraindications to VATS. In addition to general contraindications such as recent myocardial infarction and severe coagulopathy, specific contraindications include pleural obliteration and severe underlying lung disease or poor lung function. Prior operation in the ipsilateral chest should not be regarded as a contraindication (28). Adhesions can usually be divided using a combination of sharp and blunt dissection under videoscopic vision. However, patients with difficult adhesions may be more suitable for thoracotomy.

Patients who are elderly with multiple comorbidities may benefit from a chemical pleurodesis (we prefer talc slurry) if the lung can be fully re-expanded (3). Patients with severe underlying lung disease or poor lung function may not be able to tolerate selective one-lung ventilation during general anesthesia, which is used by many thoracic surgeons to gain room for instrument manoeuvring. Simple procedures in infants may be performed using endotracheal intubation with lowered tidal volume alone or intermittent apnea (10). Some thoracoscopic procedures such as bullectomy may also be performed under local and epidural anesthesia but may only be applicable to a selected group of patients (29). Thus, treatment of secondary SP (with established lung pathology) requires more clinical judgement. In addition, clinicians should bear in mind the higher mortality rate associated with VATS for secondary SP compared with PSP (30).

The recurrence rate of SP after VATS (2\% to $14 \%$ ) may be slightly higher than the minithoracotomy ( $0 \%$ to $7 \%$ ) approach (4); this difference between the techniques may reflect the inadequate exposure of the chest cavity in VATS, and subsequent incomplete detection and resection of apical bullae (4). Additionally, a change to thoracotomy from VATS is required in 2\% to $10 \%$ of patients with PSP and up to $29 \%$ of patients with secondary SP because of technical difficulties associated with the procedure.

Most complications after VATS for pneumothorax are not serious. Persistent air leak, wound infection or bleeding, intercostal neuralgia and surgical emphysema are the more common complaints (23). Rarely, re-expansion pulmonary edema can occur post-VATS $(0.15 \%)$, which can be treated with oxygen, continuous positive airway pressure or full ventilatory support in severe cases $(23,31)$. 


\section{Other therapeutic modalities}

Different types of glue have been investigated to aid in stopping pulmonary air leaks. In a recent murine study, the collagen-polysaccharide glue was well tolerated and effective in sealing air leaks without increasing adhesion formation (32). Additionally, intrapleural infusion of diluted fibrin glue as a sclerosing sealing agent in high risk patients with intractable pneumothorax and prolonged air leaks after lung resection also has shown some promising results (33). However, further clinical trials are needed to elucidate the role of glue in the management of SP.

Another recent invention is the rotating electrical brush system in mechanical pleurodesis for VATS for the treatment of SP. The brush system, when combined with VATS, was shown to be a highly effective and safe treatment for SP. The drainage time, hospitalization time and recurrence rate are comparable with other forms of pleurodesis in VATS (34).

It is very important to be able to detect and remove pulmonary bullae and blebs in the treatment of SP. A special thoracoscope using near infrared rays can allow detailed and effective imaging of the pleural and subpleural lesions because of its permeability to tissue, thus identifying small blebs and bullae, as well as being able to define better the margins of pulmonary resection (35).

\section{CURRENT RESULTS}

There have been numerous studies reporting the effectiveness of VATS in the treatment of SP, and the techniques described above have all been used with minimal morbidity (Table 1). At experienced centres, the recurrence rate after VATS has consistently been reported to be as low as with treatment via thoracotomy $(21,23-25,36)$. Furthermore, recently available long term (up to 53 months) data showed that pneumothorax recurrence rates remained low for patients treated by VATS for SP $(20,37)$. Thorough pleural examination and the experience of the surgeon may be the two most important factors in determining recurrence rate and prolonged air leaks. Often, recurrences are more frequent in patients in whom no blebs or bullae are identified (37). Missed bullae and more conservative surgical procedures in these patients are likely explanations. Some evidence suggests that apical lung excision, even in the absence of a visible lesion, may reduce SP recurrence (37).

The results from patient series have consistently concluded that stapled bullectomy is a safe and reliable method, which is unlikely to be complicated by prolonged air leak and pneumothorax recurrence, particularly when used with a form of pleurodesis $(20,24,25,36,38)$. One of the most popular is apical abrasion pleurodesis, which is preferred by the authors, and is often performed with Marlex mesh (CR Bard, USA) $(20,24,25)$. The alternative of dry gauze abrasion pleurodesis is less effective and is associated with higher pneumothorax recurrence (37). Irrespective of the material used, thorough pleural abrasion remains key to reducing pneumothorax recurrence $(21,23)$. However, some reports have suggested that apical pleurec- tomy may be marginally better in preventing pneumothorax recurrences than abrasion pleurodesis $(16,37)$, although the risk of bleeding and postoperative neuralgia is higher (16), and it is likely to make future thoracic surgery difficult. In addition, talc pleurodesis was associated with a lower SP recurrence when compared with (subtotal) pleurectomy (36). Acromycin pleurodesis, when used with stapled bullectomy, has been reported to have significantly lower SP recurrence than stapled bullectomy alone (38).

The results from endoloop bullous ligation in terms of postoperative prolonged air leak, hospital stay and pneumothorax recurrence has generally been comparable with other bullectomy procedures, particularly when applied to small bullae $(24,25)$. However, Cardillo et al (36) reported that bulla ligation had a significantly higher pneumothorax recurrence rate compared with stapled bullectomy during a mean postoperative follow-up of 38 months. On the whole, we believe that endoloop bullous ligation is viable, safe and cost effective in selected cases.

Argon beam coagulation (ABC) was shown to be less effective than stapled, suturing or endoloop ligation bullectomy in several patient series $(24,25)$. Patients treated with $\mathrm{ABC}$ had more postoperative prolonged air leaks (longer than 10 days), as well as pneumothorax recurrences $(24,25)$. Thus, the consensus is that $A B C$ should not be used as the primary treatment modality for SP.

The surgical treatment of bilateral pneumothoraces can be completed simultaneously or in stages. Patients who underwent simultaneous bilateral VATS (bleb resection and pleurodesis) for bilateral SP had similar recovery and recurrence rates compared with patients who had staged bilateral VATS (39). In addition, a separate study found the simultaneous VATS procedure to be both effective and safe, with excellent long term results (40). Therefore, simultaneous bilateral VATS should be considered in selected patients requiring bilateral surgery for pneumothorax, instead of staged bilateral VATS, bilateral thoracotomy or median sternotomy.

Secondary pneumothorax treated by VATS resulted in similar rates of postoperative prolonged air leaks and recurrence compared with thoracotomy or PSP treated by VATS (Table 1) $(20,25)$. However, the length of hospital stay was longer for secondary SP patients treated by VATS (mean eight days) compared with PSP patients treated by VATS (mean four days) (20).

\section{SUMMARY}

Technological advancements over the past decade and the introduction of VATS have changed the management strategy for SP. The advantages offered by VATS, ranging from lesser postoperative pain to shorter hospital stays, cannot be disputed, and evidence of lesser inflammatory response after VATS compared with open procedures is emerging. Perhaps most importantly, VATS is increasingly being accepted and preferred by patients and referring physicians. Minimal access surgery need not be expensive, and we have discussed a number of cost-containing strategies. We have reviewed 
the most recent published data and our own patient series, highlighting the various VATS techniques in the treatment of pneumothorax and their efficacy. The results from the past decade indicate that VATS is a quick, safe and effective treatment for SP, with recurrence rates that are comparable with open procedures. Hence, VATS should be the gold standard in the treatment of SP. However, selecting the cor-

\section{REFERENCES}

1. Jacobaeus HC. Ueber die Möglichkeit die Zystoskopic bei untersuchung seroser hohlungen anzuwenden. München Med Wochenschr 1910;57:2090-2.

2. Braimbridge MV. Thoracoscopy: a historical perspective. In: Yim AP, Hazelrigg SR, Izzat MB, Landreneau RJ, Mack MJ, Naunheim KS, eds. Minimal Access Cardiothoracic Surgery. Philadelphia: WB Saunders, 1999.

3. Baumann MH, Strange C, Heffner JE, et al. Management of spontaneous pneumothorax. An American College of Chest Physicians Delphi Consensus Statement. Chest 2001;119:590-602.

4. Sahn SA, Heffner JE. Primary care: spontaneous pneumothorax. N Engl J Med 2000;342:868-74.

5. Weisberg D, Refaely Y. Pneumothorax: Experience with 1,199 patients. Chest 2000;117:1279-85.

6. Tschopp JM, Bollinger CT, Boutin C. Treatment of spontaneous pneumothorax: Why not simple talc pleurodesis by medical thoracoscopy? Respiration 2000;67:108-11.

7. Sihoe ADL, Yim APC, Lee TW, et al. Can CT scanning be used to select patients with unilateral primary spontaneous pneumothorax for bilateral surgery? Chest 2000;118:380-3.

8. Yim APC. Video assisted thoracoscopic surgery (VATS) in Asia: Its impact and implications. Aust N Z J Med 1997;27:156-9.

9. Yim APC. Thoracoscopic surgery in the elderly population. Surg Endosc 1996;10:880-2.

10. Yim APC, Low JM, Ng SK, Ho JKS, Liu K. Video assisted thoracoscopic surgery in the paediatric population. J Paediatr Child Health 1995;31:192-6.

11. Yim APC. Minimising chest wall trauma in video-assisted thoracic surgery. J Thorac Cardiovasc Surg 1995;109:1255-6.

12. Yim APC, Wan S, Lee TW, Arifi AA. VATS lobectomy reduces cytokine responses compared with conventional surgery. Ann Thorac Surg 2000;70:243-7.

13. Leaver HA, Craig SR, Yap PL, Walker WS. Lymphocyte responses following open and minimally invasive thoracic surgery. Eur J Clin Invest 2000;30:230-8.

14. Stammberger U, Steinacher C, Hillinger S, Schmid RA, Kinsbergen T, Weder W. Early and long-term complaints following video-assisted thoracoscopic surgery: evaluation in 173 patients. Eur J Cardiothorac Surg 2000;18:7-11.

15. Hutter J, Miller K, Moritz E. Chronic sequels after thoracoscopic procedures for benign diseases. Eur J Cardiothorac Surg 2000;17:687-90.

16. Chan P, Clarke P, Daniel FJ, Knight SR, Seevanayagam S. Efficacy study of video-assisted thoracoscopic surgery pleurodesis for spontaneous pneumothorax. Ann Thorac Surg 2001;71:452-4.

17. Singh VS. The surgical treatment of spontaneous pneumothorax by parietal pleurectomy. Scand J Thorac Cardiovasc Surg 1982;16:75-80.

18. Brock H, Rieger R, Gabriel C, Polz W, Moosbauer W, Necek S. Haemodynamic changes during thoracoscopic surgery the effects of one-lung ventilation compared with carbon dioxide insufflation. Anaesthesia 2000;55:10-6.

19. Yim APC. Minimizing chest wall trauma in video-assisted thoracic surgery. J Thorac Cardiovasc Surg 1995;109:1255-6.

20. Hatz RA, Kaps MF, Meimarakis G, Loehe F, Müller C, Fürst H. Long-term results after video-assisted thoracoscopic surgery for rect procedures and patients, as well as knowing the limitations of the surgeons and the techniques, are paramount for success. Even to this day, there are considerable variations in the treatment of pneumothorax; large scale controlled studies are needed to define better the timing of surgery and the role of the different procedures in the treatment and prevention of SP. first-time and recurrent spontaneous pneumothorax. Ann Thorac Surg 2000;70:253-7.

21. Yim APC. Negative outcomes following video-assisted thoracic surgery. Asian Cardiovasc Thorac Ann 1996:4:133-8.

22. Yim APC, Ho JKS, Ng SK, Lai CKW, Buckley T. The use of a bovine pericardial buttress in the bilateral staple resection of emphysematous bullae. Hong Kong Med J 1996;2:429-32.

23. Yim APC, Liu HP. Complications and failures of video-assisted thoracic surgery: experience from two centres in Asia. Ann Thorac Surg 1996;61:538-41.

24. Yim APC, Liu HP. Video-assisted thoracoscopic management of primary spontaneous pneumothorax. Surg Laparosc Endosc 1997;7:236-40.

25. Liu HP, Yim APC, Izzat BM, Lin PJ, Chang CH. Thoracoscopic surgery for spontaneous pneumothorax. World J Surg 1999;23:1133-6.

26. Liu HP, Chang CH, Lin PJ, Chu JJ, Hsieh MJ. An alternative technique in the managementof bullous emphysema thoracoscopic endoloop ligation of bulla. Chest 1997;111:489.

27. Reid CJ, Burgin GA. Video-assisted thoracoscopic surgical pleurodesis for persistent spontaneous pneumothorax in late pregnancy. Anaesth Intensive Care 2000;28:208-10.

28. Yim APC, Liu HP, Hazelrigg SR, et al. Thoracoscopic operations on reoperated chests. Ann Thorac Surg 1998;65:328-30.

29. Yim APC, Izzat MB. Therapeutic thoracoscopy under local anesthesia. Chest 1997;111:1785.

30. Waller DA, Forty J, Morritt GN. Video-assisted thoracoscopic surgery versus thoracotomy for spontaneous pneumothorax. Ann Thorac Surg 1994;58:372-7.

31. Iqbal M, Multz AS, Rossoff LJ, Lackner RP. Reexpansion pulmonary edema after VATS successfully treated with continuous positive airway pressure. Ann Thorac Surg 2000;70:669-71.

32. Feito BA, Rath AM, Longchampt E, Azorin J. Experimental study on the in vivo behaviour of a new collagen glue in lung surgery. Eur J Cardiothorac Surg 2000;17:8-13.

33. Kinoshita T, Miyoshi S, Katoh M, et al. Intrapleural administration of a large amount of diluted fibrin glue for intractable pneumothorax. Chest 2000;117:790-5.

34. Maier A, Anegg U, Renner H, et al. Four-year experience with pleural abrasion using a rotating brush during video-assisted thoracoscopy. Surg Endosc 2000;14:75-8.

35. Suzuki T, Kitami A, Suzuki S, et al. Infrared observation during thoracoscopic surgery for bullous disease. J Thorac Cardiovasc Surg 2000;119:182-4.

36. Cardillo G, Facciolo F, Giunti R, et al. Videothoracoscopic treatment of primary spontaneous pneumothorax: a 6-year experience. Ann Thorac Surg 2000;69:357-61.

37. Ayed AK, Al-Din HJ. The results of thoracoscopic surgery for primary spontaneous pneumothorax. Chest 2000;118:235-8.

38. Loubani M, Lynch V. Video assisted thoracoscopic bullectomy and acromycin pleurodesis: an effective treatment for spontaneous pneumothorax. Resp Med 2000;94:888-90.

39. Yim APC. Simultaneous vs staged bilateral video-assisted thoracoscopic surgery. Surg Endosc 1996;10:1029-30.

40. Lang-Lazdunski L, de Kerangal X, Pons F, Jancovici R. Primary spontaneous pneumothorax: one-stage treatment by bilateral videothoracoscopy. Ann Thorac Surg 2000;70:412-7. 


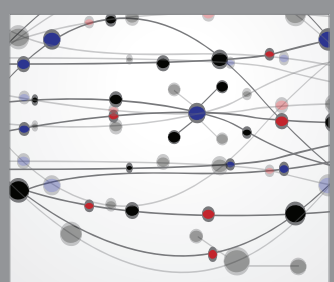

The Scientific World Journal
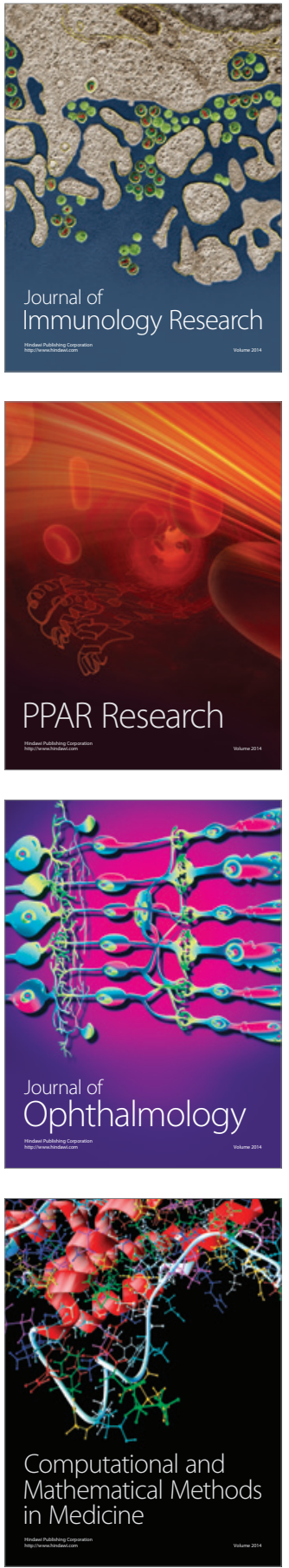

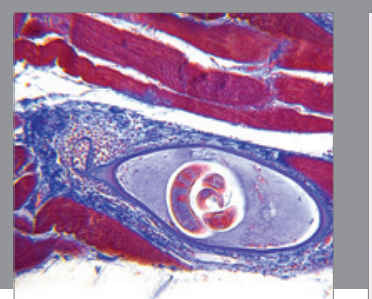

Gastroenterology Research and Practice

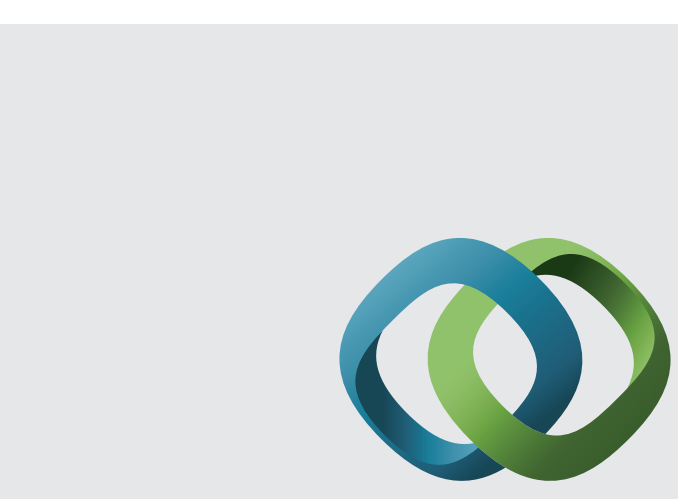

\section{Hindawi}

Submit your manuscripts at

http://www.hindawi.com
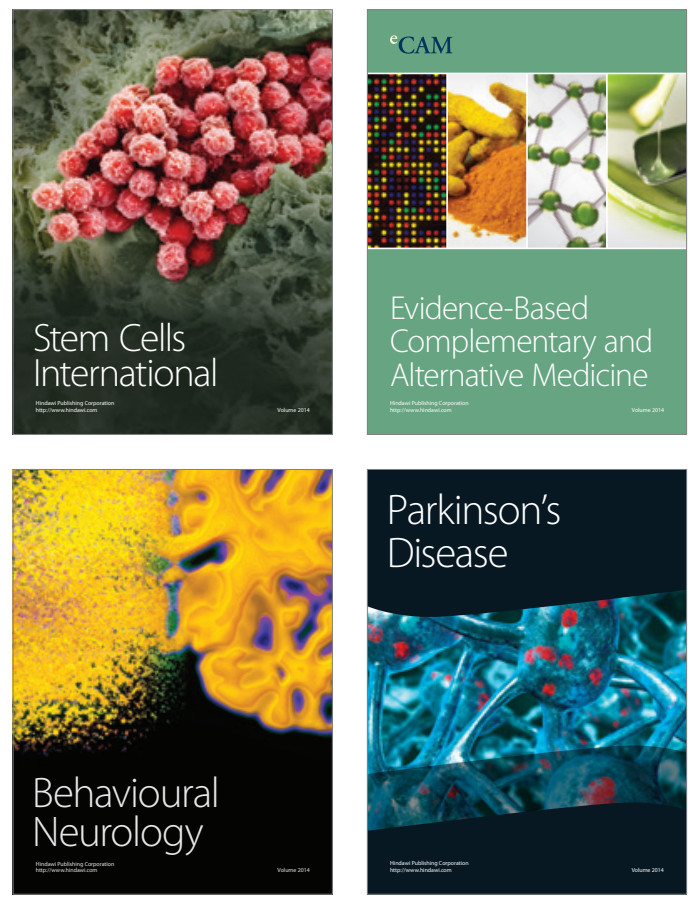
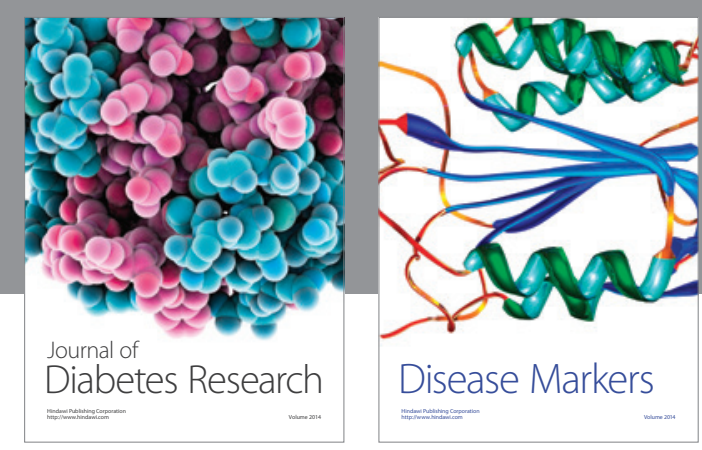

Disease Markers
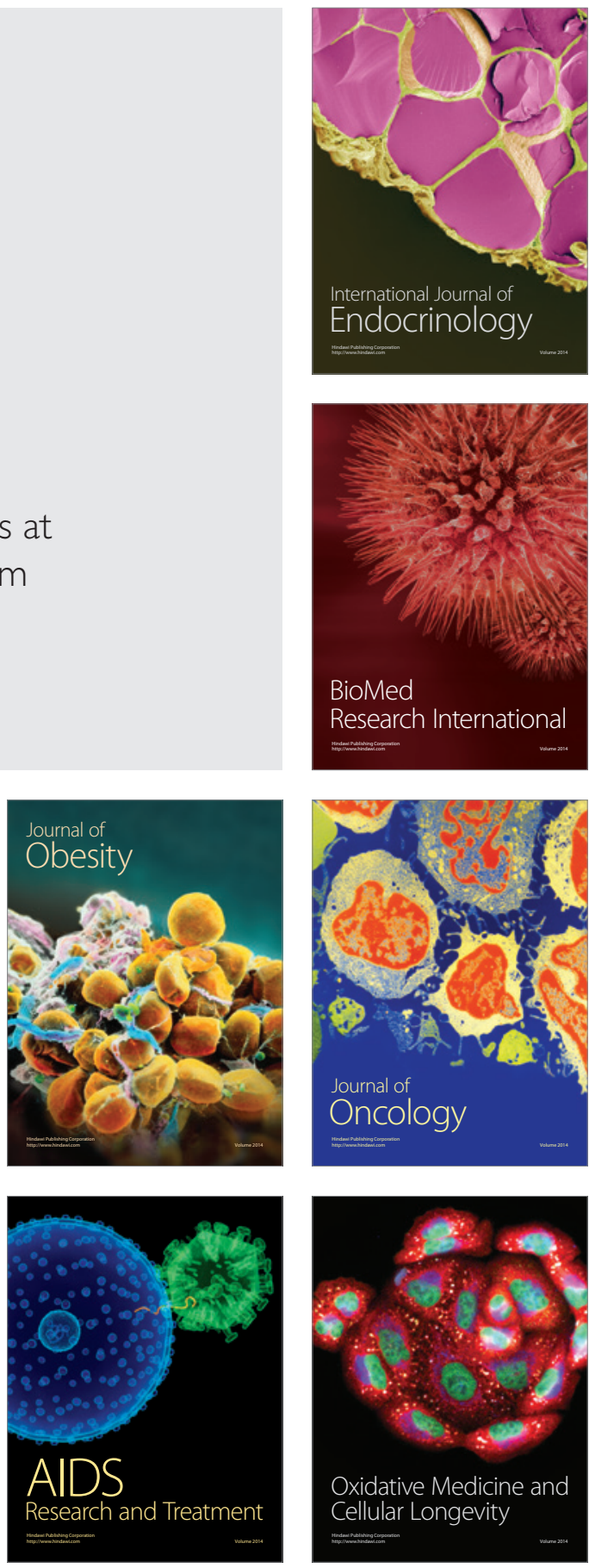